ORIGINAL ARTICLE

\title{
All naturally occurring autoantibodies against the NMDA receptor subunit NR1 have pathogenic potential irrespective of epitope and immunoglobulin class
}

\author{
E Castillo-Gómez ${ }^{1,9}$, B Oliveira ${ }^{1,9}$, D Tapken ${ }^{2,9}$, S Bertrand ${ }^{3}$, C Klein-Schmidt ${ }^{2}$, H Pan ${ }^{1}$, P Zafeiriou ${ }^{4}$, J Steiner ${ }^{5}$, B Jurek ${ }^{6,7}$, R Trippe ${ }^{2}$,

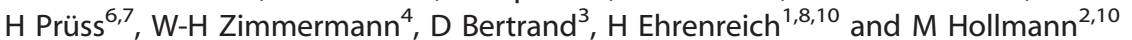

\begin{abstract}
Autoantibodies of the IgG class against $N$-methyl-D-aspartate-receptor subunit NR1 (NMDAR1) were first described in anti-NMDAR encephalitis and seen as disease indicators. Recent work on together over 5000 individuals challenged this exclusive view by showing age-dependently up to $>20 \%$ NMDAR1-autoantibody seroprevalence with comparable immunoglobulin class and titer distribution across health and disease. The key question therefore is to understand the properties of these autoantibodies, also in healthy carriers, in order to assess secondary complications and possible contributions to neuropsychiatric disease. Here, we believe we provide for human NMDAR1-autoantibodies the first comprehensive analysis of their target epitopes and functionality. We selected sera of representative carriers, healthy or diagnosed with very diverse conditions, that is, schizophrenia, age-related disorders like hypertension and diabetes, or anti-NMDAR encephalitis. We show that all positive sera investigated, regardless of source (ill or healthy donor) and immunoglobulin class, provoked NMDAR1 internalization in human-induced pluripotent stem cellderived neurons and reduction of glutamate-evoked currents in NR1-1b/NR2A-expressing Xenopus oocytes. They displayed frequently polyclonal/polyspecific epitope recognition in the extracellular or intracellular NMDAR1 domains and some additionally in NR2A. We conclude that all circulating NMDAR1-autoantibodies have pathogenic potential regarding the whole spectrum of neuronal NMDAR-mediated effects upon access to the brain in situations of increased blood-brain-barrier permeability.
\end{abstract}

Molecular Psychiatry (2017) 22, 1776-1784; doi:10.1038/mp.2016.125; published online 9 August 2016

\section{INTRODUCTION}

Circulating autoantibodies $(A B)$ directed against brain epitopes have long been documented, mainly in connection with classical autoimmune diseases or paraneoplastic syndromes. ${ }^{1-4} \mathrm{AB}$ targeting the $\mathrm{N}$-methyl-D-aspartate-receptor subunit NR1 (NMDAR1; new nomenclature GluN1 disregarded here for consistency with the respective literature, except in the molecular biological section) have attracted considerable attention lately. NMDAR1-AB of the $\lg G$ class were first described in connection with a condition named anti-NMDAR encephalitis ${ }^{5}$ and induced a flood of publications, among them many case reports. In several of them, immunosuppressive treatment of seropositive subjects is recommended. ${ }^{6-8}$ Anti-NMDAR encephalitis symptoms typically include psychosis, cognitive decline, seizures, dyskinesia, decreased consciousness and autonomic instability. ${ }^{5}$ These symptoms are reminiscent of those found upon NMDAR antagonism by ketamine, MK801, or related drugs, and have been explained by reduced surface expression of NMDAR1 upon exposure to NMDAR1-AB. ${ }^{5}$

Rendering the situation more complex, a high age-dependent seroprevalence of NMDAR1-AB has been recognized recently. ${ }^{9-14}$ According to these findings in meanwhile $>5000$ subjects, any 40 -year-old person has an $~ 10 \%$, any 80 -year-old person an $\sim 20 \%$ chance of displaying NMDAR1-AB seropositivity. ${ }^{11}$ Disease groups, ranging from schizophrenia and major depression, over multiple sclerosis, Parkinson's and Alzheimer's disease, to hypertension, diabetes and stroke, as well as healthy individuals, share not only similar NMDAR1-AB seroprevalence but also immunoglobulin (Ig) class distribution ( $\lg M, \lg A$ and $\lg G$ ) and titer range. ${ }^{9-11,13}$ These unexpected results raised the question of functionality and relevance of the highly seroprevalent NMDAR1-AB. In translational mouse studies, similar effects of the different classes (IgG, IgM and $\lg A$ ) of NMDAR1-AB on behavioral readouts were observed. ${ }^{9}$ Likewise, in a human study, an equivalent impact of circulating NMDAR1-AB of all three isotypes on evolution of lesion size after ischemic stroke was noticed. ${ }^{11}$ Detectable neuropsychiatric consequences of circulating NMDAR1-AB of all three classes were restricted to individuals with compromised blood-brain-barrier, for example, $A p o E / A P O E$ carrier status, both clinically and experimentally. ${ }^{9,11,15}$ In studies using rodent hippocampal neurons, we found NMDAR1 internalization upon NMDAR1-AB $(\lg M, \lg A, \lg G)$ binding as explanation of its reduced surface expression. ${ }^{9,15}$ A comparable finding had previously been described only for $\operatorname{lgG}$. $^{5,16}$

${ }^{1}$ Clinical Neuroscience, Max Planck Institute of Experimental Medicine, Göttingen, Germany; ${ }^{2}$ Department of Biochemistry I - Receptor Biochemistry, Ruhr University, Bochum, Germany; ${ }^{3} \mathrm{HiQscreen}$, Geneva, Switzerland; ${ }^{4}$ Institute of Pharmacology and Toxicology, University Medical Center, Göttingen, Germany; ${ }^{5}$ Department of Psychiatry, University of Magdeburg, Magdeburg, Germany; ${ }^{6}$ Department of Neurology, Charité, University Medicine, Berlin, Germany; ${ }^{7}$ German Center for Neurodegenerative Disorders (DZNE), Berlin, Germany and ${ }^{8} \mathrm{DFG}$ Research Center for Nanoscale Microscopy and Molecular Physiology of the Brain (CNMPB), Göttingen, Germany. Correspondence: Professor H Ehrenreich, Clinical Neuroscience, Max Planck Institute of Experimental Medicine, Hermann-Rein-Strasse 3, Göttingen 37075, Germany.

E-mail: ehrenreich@em.mpg.de

${ }^{9}$ These authors share first authorship.

${ }^{10}$ These authors share last authorship.

Received 18 March 2016; revised 3 May 2016; accepted 1 June 2016; published online 9 August 2016 
Table 1. Overview of donors of NMDAR1-AB-positive and -negative serum samples

\begin{tabular}{|c|c|c|c|}
\hline & Seropositive individuals $(\mathrm{N}=14)$ & Seronegative individuals $(\mathrm{N}=15)$ & P-value \\
\hline Age at examination, mean \pm s.d., years ${ }^{b}$ & $62.87 \pm 24.44$ & $65.24 \pm 10.99$ & 0.234 \\
\hline \multicolumn{4}{|l|}{ Diagnosis, No. $(\%)^{\mathrm{a}}$} \\
\hline Healthy & $2(14.3)$ & $4(26.7)$ & \multirow{5}{*}{0.418} \\
\hline NMDAR1-AB encephalitis & $2(14.3)$ & $0(0.0)$ & \\
\hline Psychiatric conditions $^{c}$ & $1(7.1)$ & $1(6.3)$ & \\
\hline Diabetes and hypertension & $2(14.3)$ & $1(6.7)$ & \\
\hline Other medical conditions ${ }^{\mathrm{d}}$ & $0(0.0)$ & $1(6.7)$ & \\
\hline \multicolumn{4}{|l|}{ NMDAR1-AB seroprevalence, titers, No. $^{\mathrm{e}}$} \\
\hline $\lg A(1: 10 ; 1: 32 ; 1: 100 ; 1: 320 ; 1: 1000 ; 1: 3200)$ & $2 ; 0 ; 0 ; 0 ; 4 ; 0$ & & \multirow{3}{*}{$\mathrm{n} / \mathrm{a}$} \\
\hline $\lg (1: 10 ; 1: 32 ; 1: 100 ; 1: 320 ; 1: 1000 ; 1: 3200)$ & $0 ; 0 ; 1 ; 1 ; 1 ; 1$ & & \\
\hline $\lg M(1: 10 ; 1: 32 ; 1: 100 ; 1: 320 ; 1: 1000 ; 1: 3200)$ & $0 ; 0 ; 1 ; 1 ; 5 ; 1$ & & \\
\hline
\end{tabular}

Considering the high seroprevalence of NMDAR1-AB across health and disease, the key question is to understand the properties of these $A B$, also in healthy carriers, in order to assess secondary complications and possible contributions to neuropsychiatric disease, for example, cognitive decline, psychotic symptoms or epileptic seizures. Are they like a 'ticking time bomb' once the blood barrier opens?

Here, we believe we provide for human NMDAR1-AB the first comprehensive analysis of their target epitopes and of functionality. We investigated whether NMDAR1-AB of different lg classes, derived from sera of subjects with very diverse conditions, would (i) reveal functionality in an internalization assay using human induced pluripotent stem cell (IPSC)-derived cortical neurons; (ii) lead to electrophysiological consequences in NR1-1b/NR2Aexpressing Xenopus oocytes; and (iii) be directed against the same or against different epitopes of NMDAR1.

We report as most important take-home message that, independent of any medical condition or lg class, NMDAR1-AB are functional, leading to decreased NMDAR surface expression and reduced glutamate-evoked currents. The $A B$ recognize epitopes in the extracellular and/or intracellular NMDAR1 domains and, surprisingly, some positive sera also in the NR2A subunit of NMDAR. Thus, most intriguingly, they all have potentially (patho) physiological relevance regarding brain functions.

\section{MATERIALS AND METHODS}

All experiments were performed by researchers unaware of group assignment ('fully blinded').

\section{Human samples}

Serum specimens $(N=29)$ from our phenotyping/biomarker trials $8,10,11,17$ were selected to (i) cover a spectrum of diseases and health, (ii) include all NMDAR1-AB Ig classes and (iii) build on enough material for extensive testing (Table 1). In addition, samples ( $N=7$; few $\mu$ l available) for targeted epitope mapping were obtained from anti-NMDAR encephalitis patients (Charité, HP). Subject data/human materials (including IPSC) were collected according to ethical guidelines/Helsinki Declaration including subjects' informed consent.

\section{NMDAR1-AB titer determination}

Recombinant immunofluorescence tests (Euroimmun, Lübeck, Germany), clinical standard procedures, were used to detect NMDAR1-AB, based on
HEK293T cells transfected with NMDAR1, ${ }^{5,6}$ and secondary $A B$ against human $\mathrm{lgG}$, IgM or $\lg A$. Results were independently assessed by three investigators.

Dialysis of serum samples

Functional studies were conducted with sera following ammonium sulfate precipitation of immunoglobulins ${ }^{18}$ and dialysis (Slide-A-Lyzer MiniDialysis-Units, 10000 MWCO Plus Float, Thermo Fisher Scientific, Rockford, IL, USA).

Reprogramming of human fibroblasts and differentiation into neurons

Human fibroblasts from gingiva biopsies were reprogrammed using STEMCCA system (Merck Millipore, Darmstadt, Germany) for introduction of OCT4, SOX2, KLF4 and c-MYC. ${ }^{19}$ Clones were tested for pluripotency markers following standard procedures. ${ }^{19}$ After reprogramming, IPSC was adapted to feeder-free culture system (Matrigel matrix, Corning, Wiesbaden, Germany) and TeSR ${ }^{\mathrm{TM}}$-E8 ${ }^{\mathrm{TM}}$ medium (Stem Cell Technologies, Cologne, Germany). Neural induction was based on dual SMAD inhibition (Figure 1a). ${ }^{20}$

\section{Endocytosis assay}

Human IPSC-derived cortical neurons grown on coverslips, 70 days post neural induction, were pre-cooled on ice $(10 \mathrm{~min})$, and washed $3 \times$ with cold HBSS (Hank's balanced salt solution; Life Technologies, Darmstadt, Germany). Culture media were kept at 37 or $4{ }^{\circ} \mathrm{C}$. Neurons were incubated (30 min) in cold HBSS with 1:100 diluted sera (14 seropositive; 6 seronegative), control NMDAR1-AB (M68, mouse IgG, SYSY, Göttingen, Germany) or HBSS alone (negative control). After three HBSS washes to remove unbound $A B$, neurons were returned to their media and incubated for $20 \mathrm{~min}$ at $37^{\circ} \mathrm{C}$ ( 2 coverslips/sample, to allow endocytosis) or $4{ }^{\circ} \mathrm{C}$ (1 coverslip/sample, endocytosis control). After ice-cold HBSS wash, coverslips were kept on ice $(5 \mathrm{~min})$. Remaining surface NMDAR1 was exposed to a mouse NMDAR1-AB (N-terminal; Abcam, Cambridge, UK, 1:100), $10 \mathrm{~min}$ on ice, followed (after ice-cold HBSS wash) by secondary donkey anti-mouse IgG (Life Technologies, Alexa-Fluor546, 1:100) for 10 min on ice in dark, and finally three ice-cold HBSS washes to remove unbound $A B$. Neurons were fixed with ice-cold $4 \%$ paraformaldehyde (30 $\mathrm{min})$ and washed $3 \times(5 \mathrm{~min})$ with $0.1 \mathrm{~m}$ phosphate-buffered saline (PBS). Then, cells were blocked and permeabilized for $1 \mathrm{~h}$ at RT (5\% normal goat, $5 \%$ normal horse, $5 \%$ fetal calf serum, $0.5 \%$ Triton $X$ in PBS), doublestained at $4{ }^{\circ} \mathrm{C}$ overnight with chicken anti-NeuN-AB (SYSY, 1:500) and secondary donkey anti-chicken AB (Life Technologies, Alexa Fluor 488, 1:250) for $1 \mathrm{~h}$ at RT (all dark) (Figure $1 \mathrm{~b}$ ). Nuclei were visualized using DAPI (Sigma-Aldrich, Munich, Germany, $0.01 \mathrm{\mu g} \mathrm{ml}^{-1}$ ). After PBS wash, 
coverslips were mounted on Super-Frost slides with Mowiol-mountingmedia (Sigma-Aldrich). Confocal laser-scanning microscopy was used to quantify cell-surface NMDAR1 density ( $\times 63$ glycerol objective; TCS-SP5 Leica-Microsystems, Mannheim, Germany). From each coverslip, Z-series of optical sections ( $0.5 \mu \mathrm{m}$ apart) covering the three-dimensional extension of neurons were acquired (sequential scanning mode, identical acquisition parameters). For analysis, $50 \mathrm{NeuN}+$ cells/coverslip were randomly selected using FIJI-ImageJ software. ${ }^{21}$ Soma profile including NMDAR1 surface expression was drawn and fluorescence intensity/cell surface area (Alexa-Fluor546) automatically measured. Background was subtracted, mean intensity for each coverslip determined and fluorescence intensity ratio $\left(37^{\circ} \mathrm{C} / 4^{\circ} \mathrm{C}\right)$ calculated.

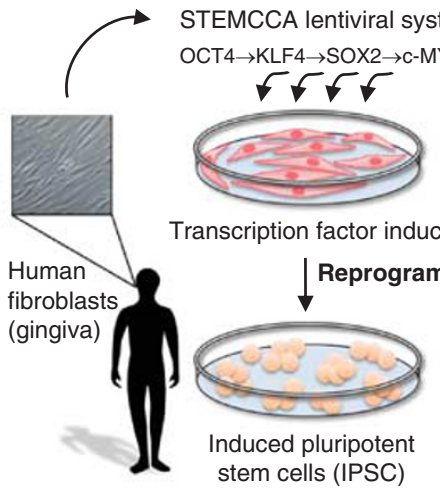

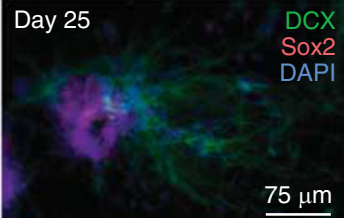

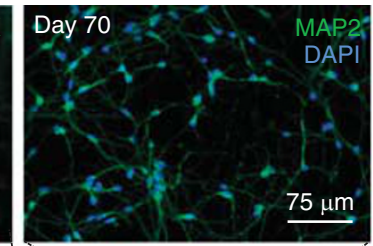

TGF- $\beta$
$\langle S B 431542\rangle$
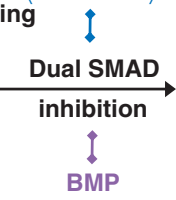

BMP $\langle$ Dorsomorphin

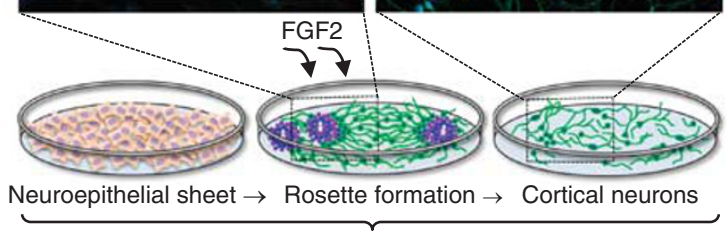

Neurogenesis

b NMDAR1 ENDOCYTOSIS ASSAY

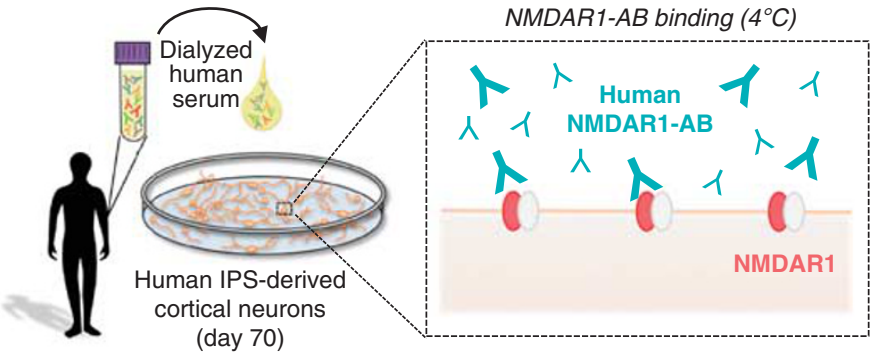

Fixation, staining and confocal microscopy

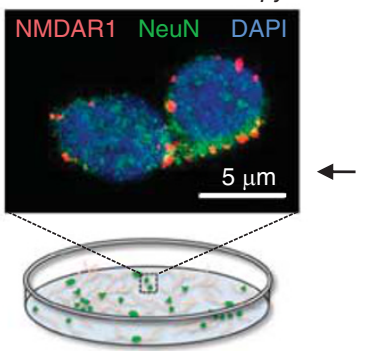

Labeling of the remaining surface NMDAR1 (step 2; $4^{\circ} \mathrm{C}$ )

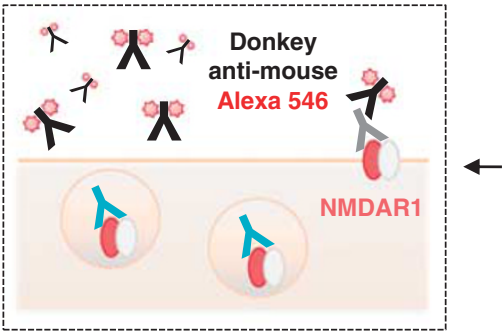

NMDAR1 endocytosis $\left(37^{\circ} \mathrm{C}\right)$
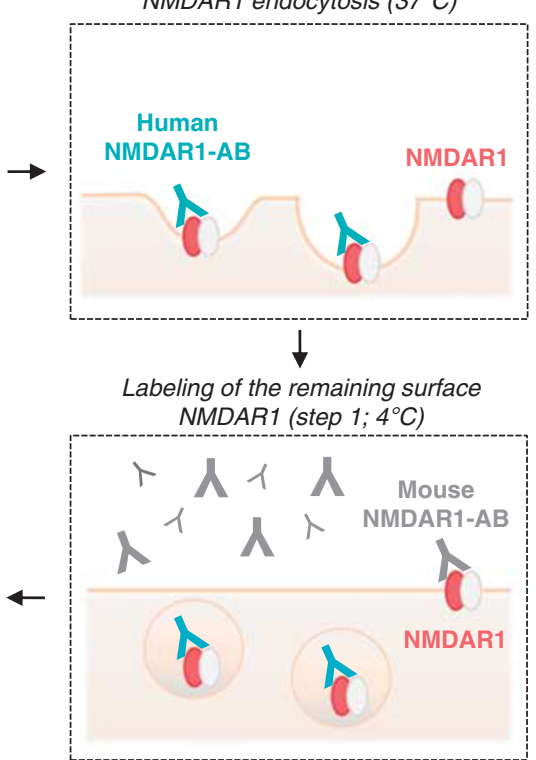

Human

NMDAR1-AB

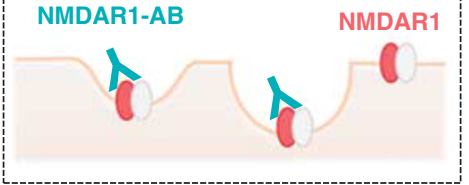

eling of the remaining surface

C EFFECT OF NMDAR1-AB ON NMDAR AVAILABILITY AT THE NEURONAL MEMBRANE
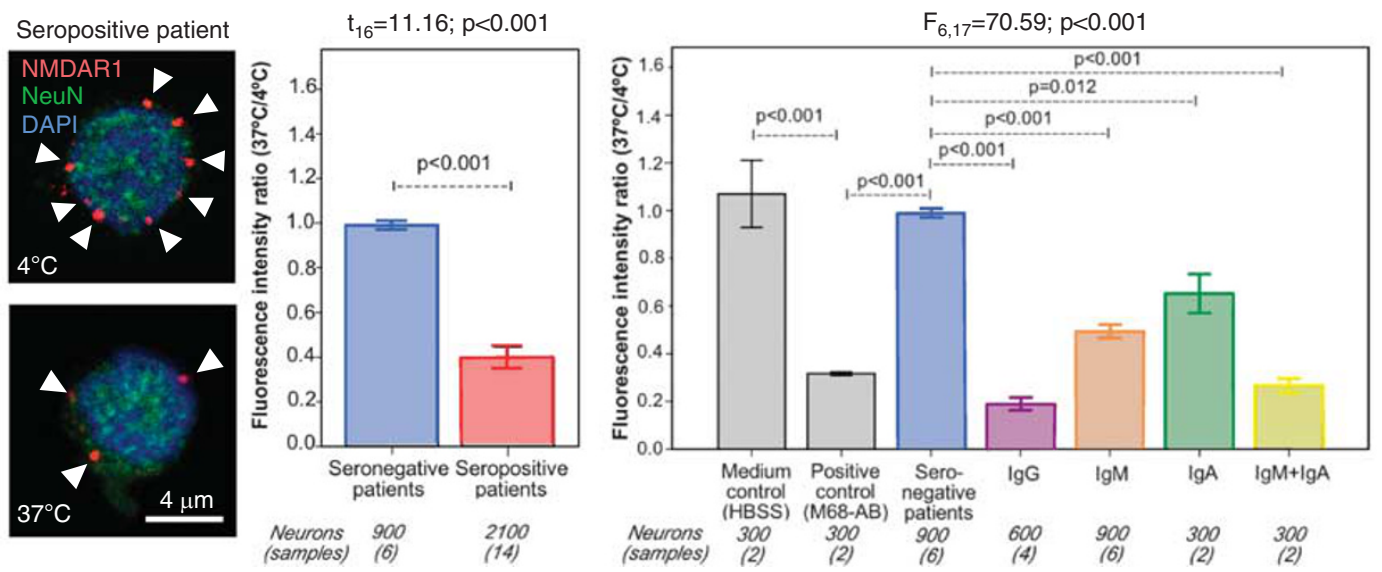
Oocyte preparation and injection

Xenopus laevis oocytes were prepared, injected and tested using standard procedures. Briefly, ovaries were harvested from Xenopus females in deep anesthesia by hypothermia $\left(4^{\circ} \mathrm{C}\right.$ ) and MS-222 (Sigma-Aldrich, $150 \mathrm{mg} \mathrm{I}^{-1}$ ). Animals were decapitated and pithed obeying animal rights (Geneva, Switzerland). A small piece of ovary was isolated for immediate preparation while the remaining part was placed at $4{ }^{\circ} \mathrm{C}$ in sterile Barth-solution

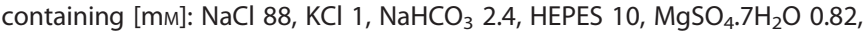
$\mathrm{Ca}\left(\mathrm{NO}_{3}\right)_{2} \cdot 4 \mathrm{H}_{2} \mathrm{O} 0.33, \mathrm{CaCl}_{2} \cdot 6 \mathrm{H}_{2} \mathrm{O} 0.41$, at $\mathrm{pH} 7.4$, supplemented with $100 \mathrm{U} \mathrm{ml}^{-1}$ penicillin/100 $\mathrm{ug} \mathrm{ml}^{-1}$ streptomycin (Life Technologies). Automatic injection of mRNAs encoding for human NMDAR (NR1-1/NR2A) was performed in batches of 95 oocytes using Roboinject ${ }^{22}$ (Multi Channel Systems, Reutlingen, Germany) (Figure 2a). Optimal expression of NMDAR was obtained with injection of $15 \mathrm{nl}$ containing $0.2 \mu \mathrm{g} \mu \mathrm{l}^{-1}$ of RNAs, ratio NR1-1b:NR2A = 1:1; mRNA was prepared using mMessage mMachine SP6 transcription kit for NR1-1b and T7 for NR2A (Thermo Fisher Scientific).

\section{Electrophysiological recordings and experimental protocol}

NMDAR activity was validated $60 \mathrm{~h}$ after mRNA injection by 2-electrode voltage clamp (Figure 2a). All electrophysiological recordings were performed using an automated HiClamp system (Multi Channel Systems) at $18{ }^{\circ} \mathrm{C}$ and with cells superfused with OR2 medium (mм: $\mathrm{NaCl} 88, \mathrm{KCl} 2.5$, HEPES 5, $\mathrm{CaCl}_{2} .2 \mathrm{H}_{2} \mathrm{O} 1.8, \mathrm{pH}$ 7.85). To chelate zinc contaminant, $10 \mu \mathrm{m}$ EDTA was added to all solutions. Unless otherwise indicated, cells were maintained at holding potential of $-80 \mathrm{mV}$ and compounds/AB incubations conducted in 96-well-microtiter plates (Thermo Fisher Scientific). Only cells displaying low leak current and responses $>0.5 \mu \mathrm{A}$ to a test pulse containing $0.3 \mu \mathrm{m}$ glutamate $/ 10 \mu \mathrm{m}$ glycine (Sigma-Aldrich) were retained for successive testing (Figures $2 \mathrm{a}$ and $\mathrm{b}$ ). Cells were then challenged with pre-incubation of $120 \mathrm{~s}$ in control medium (OR2 medium) followed by brief exposures to $0.3 \mu \mathrm{m}$ glutamate $/ 10 \mu \mathrm{m}$ glycine $(10 \mathrm{~s})$ every $2 \mathrm{~min}$ for $10 \mathrm{~min}$ (Figure 2b, steps 1 and 2). The last $4 \mathrm{~min}$ was considered as control response-amplitude to glutamate (Figure $2 c$, right-side graphs, $-4-0 \mathrm{~min}$ ). Upon stabilization, cells were exposed for $16 \mathrm{~min}$ to dialyzed serum samples (titer dilution for seropositive and 1:1000 for seronegative samples) or to positive control (M68-AB, 1:1000). NMDAR activity was tested by brief exposure to $0.3 \mu \mathrm{m}$ glutamate/10 $\mu \mathrm{m}$ glycine $(10 \mathrm{~s})$ every $2 \mathrm{~min}$ for $16 \mathrm{~min}$ in presence of the dialyzed serum (Figure $2 \mathrm{~b}$, steps 3 and 4). To evaluate the cellular response, area-under-the-curve (AUC) for each glutamate-evoked current was computed and normalized to AUC of control responses $(-4-0 \mathrm{~min})$. Data were analyzed using custom-made software (Matlab-Mathworks, Ismaning, Germany). For each sample, a mean of $\geqslant 3$ oocytes was calculated (Figure $2 c$, left-side graphs).

\section{Epitope mapping using NMDAR1 constructs}

NMDAR1 constructs were generated based on the longest splice variant, GluN1-1b (GenBank accession \#U08263; Figures 3a and b). All cDNAs (including GluN2A: \#AF001423; GluN2B: \#U11419) were cloned into
pcDNA4/TO/myc-HisA (Invitrogen, Carlsbad, CA, USA) such that the encoded receptor had a myc-His-tag connected to its C-terminus by a short peptide linker (SRGPF). Chimeras and mutants for epitope analysis were constructed by overlap-extension-PCR using chimeric or mutagenic primers. ${ }^{23,24}$ To transiently express glutamate receptor subunits, HEK293T cells were cultured in high-glucose DMEM (Life Technologies). On a 35-mm dish, 50000 cells were plated, grown for 3 days, transfected with receptor cDNA $(3 \mu \mathrm{g})$ using Metafectene-Pro (Biontex, Munich, Germany) and, $24 \mathrm{~h}$ after transfection, seeded onto poly-D-lysine-coated coverslips (Sigma-Aldrich). At 2 days after transfection, cells were fixed with $5 \%$ paraformaldehyde $(20 \mathrm{~min})$, washed $5 \times$ with $0.1 \mathrm{~m} \mathrm{PBS}$, permeabilized with $0.1 \%$ Triton $X-100(5 \mathrm{~min})$, again washed $5 \times$ with PBS, blocked for $1 \mathrm{~h}$ with $5 \%$ normal goat serum (Sigma-Aldrich). After $5 \times$ PBS washes, cells were incubated with serum (1:10-1:200) or monoclonal mouse anti-myc antibody (transfection efficiency control; self-made, purified from mouseclone-9E10) for $1 \mathrm{~h}$, washed $10 \times$ with PBS, incubated for $1 \mathrm{~h}$ with Alexa Fluor 488-labeled goat anti-human secondary AB (IgG: Southern Biotech, Birmingham, AL, USA; IgA: Jackson ImmunoResearch, West Grove, PA, USA; IgM: Thermo Fisher Scientific) or anti-mouse IgG (controls; Thermo Fisher Scientific), washed $5 \times$ with PBS, incubated with TO-PRO-3 iodide nuclearstain (Molecular Probes, Eugene, OR, USA) (15 min), and washed $5 \times$ with PBS. Cells were mounted in Fluoromount-G (Southern Biotech) and analyzed by confocal microscopy ( $63 \times$ oil objective, TCS SP2 AOBS, LeicaMicrosystems). All results are consensus judgements from at least four independent investigators of two different laboratories.

\section{Statistics}

All statistical analyses were performed using SPSS for Windows version 17.0 (IBM-Deutschland, Munich, Germany). Group differences in categorical and continuous variables were assessed using Chi-square and MannWhitney U-test. One-way or repeated-measures ANOVA, followed by multiple pair-wise comparisons with Bonferroni's post hoc correction, was employed to determine the significance of fluorescence intensity or AUC; $P$-values $<0.05$ were considered as significant; data in figures are mean \pm s.e.m.

\section{RESULTS}

In human IPSC-derived cortical neurons, exposure to all NMDAR1AB-positive sera tested, independent of Ig class and titer, led to receptor endocytosis, reflected by decreased cell-surface fluorescence intensity ratio $37^{\circ} \mathrm{C} / 4^{\circ} \mathrm{C}$ (perikaryal labeling). Negative sera had no effect (unpaired Student's t-test: $t_{16}=11.16$; $P<0.001$; seronegative samples: $n=6$, neurons $n=900$; seropositive samples: $n=14$, neurons $n=2100$ ) (Figure 1c). Analyzing the impact of Ig classes separately, significant results remained for all (one-way ANOVA: $\mathrm{F}_{6,17}=70.59 ; P<0.001$ with Bonferroni post hoc

Figure 1. NMDAR1 endocytosis in human induced pluripotent stem cell (IPSC)-derived cortical neurons after autoantibodies (AB) exposure. (a) Reprogramming strategy: Human fibroblasts obtained from gingiva biopsies were transduced using a lentiviral system to simultaneously integrate the transcription factors OCT4, KLF4, SOX2 and C-MYC. Transcription factor expression leads to cell reprogramming and colony formation of IPSC, which are differentiated into cortical neurons using a dual SMAD inhibition strategy (selective blocking of TGF- $\beta$ and BMP pathways). Cells acquire neuronal identity forming a neural stem cell monolayer. Dissociation of the neuroepithelial sheath leads to rearrangement of neural stem cells $(\mathrm{SOX} 2+)$ in a rosette-like structure, further expanded by application of the mitogen FGF2. Immature neurons $(D C X+)$ emerge from these structures during the neurogenesis period to give rise mainly to MAP2+ cortical excitatory neurons. (b) At day 70 of maturation, neurons are exposed to human sera. NMDAR1-AB binding to NMDAR1 (at $4{ }^{\circ} \mathrm{C}$ ) leads to rapid endocytosis of the receptor-antibody complex at $37^{\circ} \mathrm{C}$. The remaining cell-surface NMDAR1 is detected by combining mouse anti-NMDAR1-AB (step 1) and secondary donkey anti-mouse Alexa 546-AB (step 2). Neurons are defined as NeuN+ cells. (c) Representative confocal images of neurons exposed to an lgG seropositive sample are shown on the left. Both pictures are Z-projections of three consecutive focal planes $0.5 \mu \mathrm{m}$ apart, taken at $\times 100$ magnification under confocal laser-scanning microscope. The upper picture depicts a neuron (NeuN + , labeled in green), kept at $4{ }^{\circ} \mathrm{C}$ (no endocytosis allowed-control condition) and the lower picture a neuron at $37^{\circ} \mathrm{C}$ (endocytosis). For each serum sample, cell membrane NMDAR1 (labeled in red; arrow heads) is quantified. Degree of internalization is expressed as ratio of fluorescence intensity measured at both temperatures. Seropositive samples show reduced fluorescence intensity ratio $\left(37^{\circ} \mathrm{C} / 4^{\circ} \mathrm{C}\right) \mathrm{compared}$ with seronegative samples (graph on the left; unpaired Student's $t$-test: $t_{16}=11.16 ; P<0.001$ ), consistent with a decrease in surface NMDAR1 after exposure to NMDAR1-AB. Right graph: Fluorescence intensity ratio is lower for all seropositive samples (separate analyses shown for samples with only $\lg \mathrm{G}, \lg \mathrm{M}, \lg \mathrm{A}$ or $\lg \mathrm{M}+\lg \mathrm{A}$, in purple, orange, green and yellow columns, respectively) and the positive control (IgG M68-AB). One-way ANOVA: $\mathrm{F}_{6,17}=70.59 ; P<0.001$; multiple comparisons with Bonferroni's post hoc correction, $P$-value $<0.05$; results given as mean \pm s.e.m. BMP, bone morphogenic pathway; c-MYC, avian myelocytomatosis virus oncogene cellular homolog; DAPI, 4',6-diamidino-2-phenylindole; DCX, doublecortin; FGF2, fibroblast growth factor 2; KLF4, Krüppel-like factor 4; MAP2, microtubule-associated protein 2; NMDAR1, N-methyl-Daspartate-receptor subunit NR1; NeuN, neuronal nuclear antigen; OCT4, octamer-binding transcription factor 4; SOX2, sex determining region Y-homeobox 2; STEMCCA, stem cell cassette; TGF- $\beta$, transforming growth factor- $\beta$. 


\section{a OOCYTE PREPARATION AND VALIDATION}

hNR1-1b/NR2-A

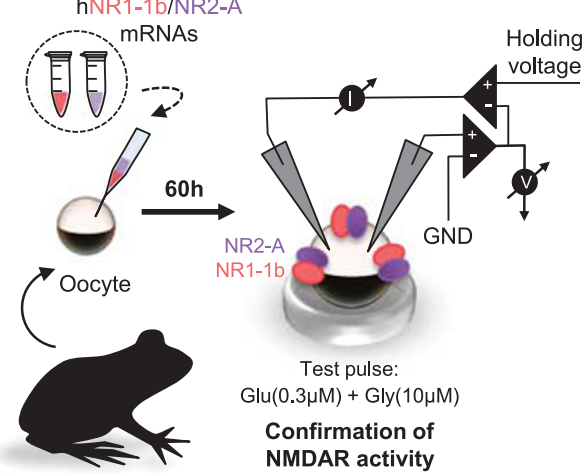

b EXPERIMENTAL PROTOCOL

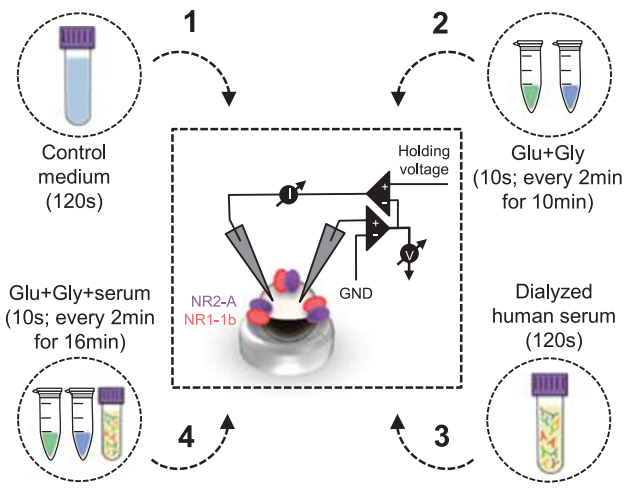

C EfFEct of NMDAR1-AB on Glutamate-Evoked Response Control medium Dialyzed human serum
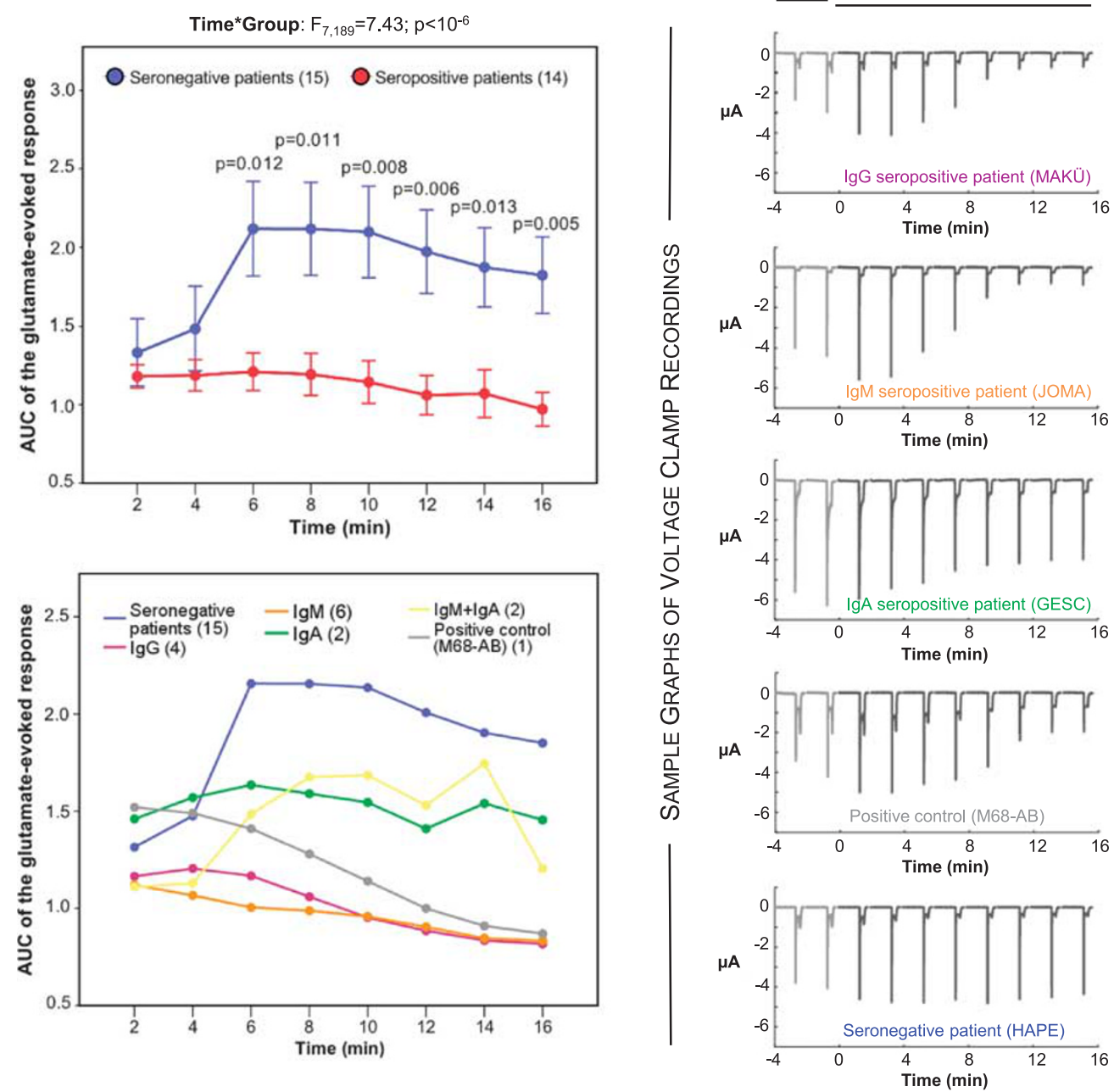

Figure 2. Decreased NMDAR activity after autoantibodies (AB) exposure. (a) NMDAR activity in Xenopus laevis oocytes expressing human NR1-1b/NR2A is confirmed using 2-electrode voltage clamp recordings. (b) Control glutamate response of each oocyte is tested after $120 \mathrm{~s}$ incubation in control medium followed by $10 \mathrm{~s}$ exposure to glutamate and glycine every 2 min for 10 min (steps 1 and 2). Cells are afterwards exposed for $120 \mathrm{~s}$ to dialyzed serum samples or to positive control (M68-AB), followed by $10 \mathrm{~s}$ exposures to glutamate and glycine every 2 min for $16 \mathrm{~min}$ (steps 3 and 4). (c) An increase in AUC of the glutamate-evoked response starting at 6 min and lasting for at least 16 min is observed in seronegative but not in seropositive samples (left upper graph; one-way repeated-measures ANOVA: time $\times$ group interaction: $\mathrm{F}_{7,189}=7.43, P<10^{-6}$; Bonferroni's post hoc correction for multiple comparison: only $P$-values $<0.05$ are shown). The left lower graph shows curves for lg classes separately which all are below the seronegative curve (one-way repeated-measures ANOVA: time $\times$ group interaction: $F_{35,168}=1.98, P=0.002$ ). On the right side, five representative recordings of cells exposed to $\lg$, IgM and IgA seropositive samples, positive control sample (M68-AB) and a seronegative sample are shown. The first two curves of every graph show the last 4 min of the control response to glutamate (see Materials and methods for detailed information). AUC, area-under-the-curve; Glu, glutamate; Gly, glycine; GND, signal ground; I, intensity; Ig, immunoglobulin; NMDAR, N-methyl-D-aspartate receptor; V, voltage. 
a TOPOLOGY \& DOMAIN STRUCTURE OF NMDAR1 (GIuN1-1b) CONSTRUCTS

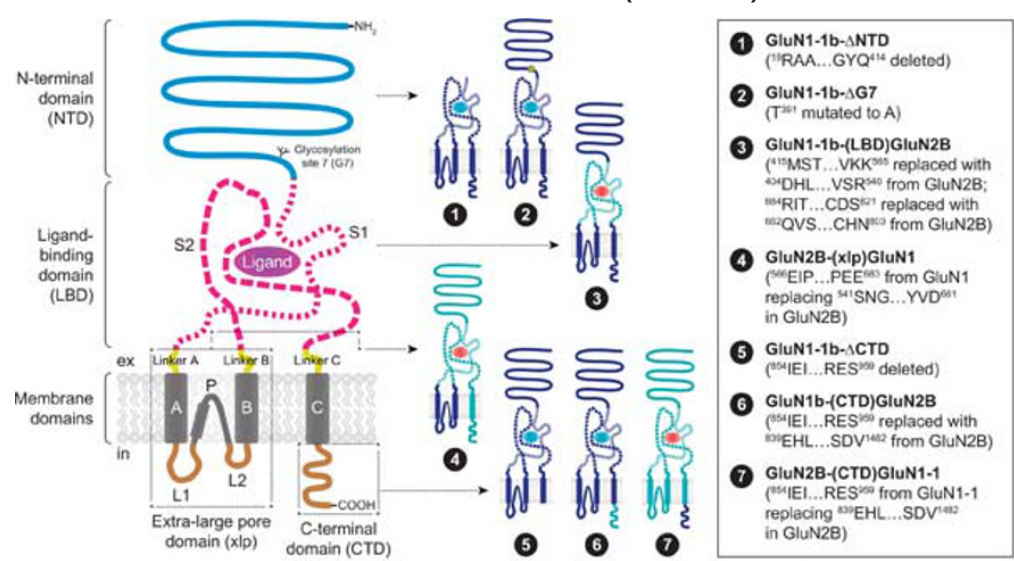

b AMINO ACID SEQUENCE \& DOMAINS OF GIUN1-1b

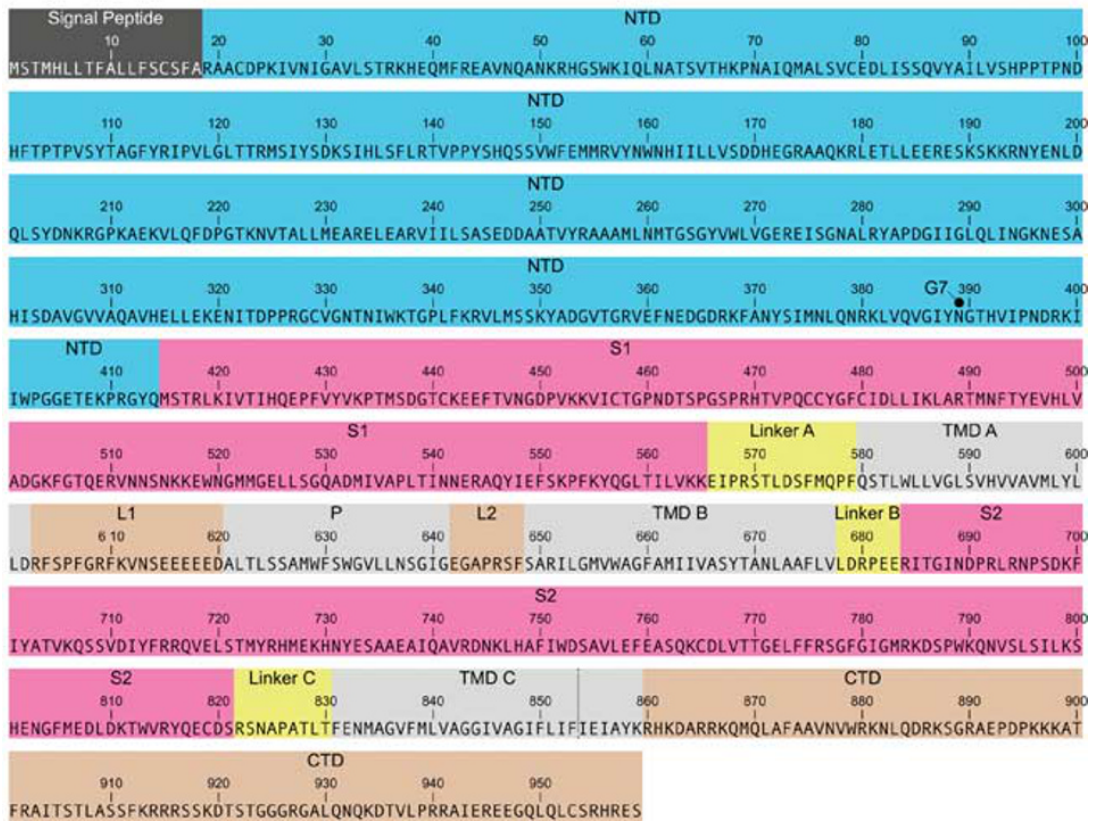

\section{NTD/G7 EPITOPES RECOGNIZED BY ANTI-NMDAR ENCEPHALITIS SERA}

\begin{tabular}{|c|c|c|c|c|c|c|c|c|}
\hline \multirow[b]{2}{*}{$\mathrm{ID}^{(\mathrm{a})}$} & \multirow[b]{2}{*}{$\mathrm{AGE}^{(\mathrm{b})}$} & \multirow[b]{2}{*}{ GENDER } & \multicolumn{3}{|c|}{ NMDAR1-AB } & \multirow[b]{2}{*}{ GluN1-1b } & \multirow[b]{2}{*}{ GluN1-1b-ANTD } & \multirow[b]{2}{*}{ GluN1-1b- $\Delta G 7$} \\
\hline & & & IG CLASS & TITER & EPITOPE & & & \\
\hline \multirow{2}{*}{ HP1 } & \multirow{2}{*}{21} & \multirow{2}{*}{$\mathrm{F}$} & $\lg G$ & $1: 100$ & NTD (G7) & + & - & - \\
\hline & & & IgM & $1: 10$ & Other & + & + & + \\
\hline \multirow{2}{*}{ HP2 } & \multirow{2}{*}{18} & \multirow{2}{*}{$\mathrm{F}$} & $\lg G$ & $1: 10$ & NTD (G7) & + & - & - \\
\hline & & & IgM & $1: 100$ & Other & + & + & + \\
\hline \multirow{2}{*}{ HP3 } & \multirow{2}{*}{30} & \multirow{2}{*}{$F *$} & $\operatorname{IgG}$ & $1: 100$ & NTD & + & - & + \\
\hline & & & IgM & $1: 100$ & Other & + & + & + \\
\hline \multirow{2}{*}{ HP4 } & \multirow{2}{*}{19} & \multirow{2}{*}{$F_{*}$} & $\operatorname{IgG}$ & $1: 100$ & Other & + & + & + \\
\hline & & & $\lg M$ & $1: 10$ & Other & + & + & + \\
\hline \multirow{2}{*}{ HP5 } & \multirow{2}{*}{27} & \multirow{2}{*}{$\mathrm{F}$} & $\operatorname{IgG}$ & $1: 10$ & NTD (G7) & + & - & - \\
\hline & & & IgM & $1: 100$ & Other & + & + & + \\
\hline \multirow{2}{*}{ HP6 } & \multirow{2}{*}{22} & \multirow{2}{*}{$\mathrm{F}$ * } & $\operatorname{IgG}$ & $1: 100$ & NTD (G7) & + & - & - \\
\hline & & & $\operatorname{Ig} A$ & $1: 1000$ & other & + & + & + \\
\hline \multirow{2}{*}{ HP7 } & \multirow{2}{*}{19} & \multirow{2}{*}{$F_{*}$} & $\lg G$ & $1: 100$ & Other & + & + & + \\
\hline & & & $\lg A$ & $1: 10$ & Other & + & + & + \\
\hline
\end{tabular}

Figure 3. GluN1-1b constructs for epitope mapping of NMDAR1-AB. (a) Topology and domain structure of the GluN1-1b constructs used. The scheme on the left side shows the membrane topology of the GluN1-1b subunit, with domains colored as in (b). Chimeras and mutagenic constructs targeting the different domains of GluN1 are explained on the right (all residue numbers include the signal peptide; GluN1 and GluN2B constructs were generated based on GenBank accession numbers U08263 and NM_012574, respectively). (b) Amino-acid sequence and domains of GluN1-1b. The position marked in the sequence as G7 (glycosylation site 7 ) is the residue to which the oligosaccharide is attached $\left(\mathrm{N}^{389}\right)$. The recognition site for this type of glycosylation is $\mathrm{N}-\mathrm{X}-\mathrm{S} / \mathrm{T}$; therefore, mutation of $\mathrm{T}^{391}$ to $\mathrm{A}$ in the construct number 2 (GluN1-1b- $\Delta$ G7) prevents glycosylation 2 residues upstream of it $\left(\mathrm{N}^{389}\right)$. (c) NTD/G7 epitopes recognized by serum NMDAR1-AB of different lg classes from seven female patients with diagnosed anti-NMDAR encephalitis. AB, antibodies; CTD, C-terminal domain; L1, intracellular loop 1; L2, intracellular loop 2; LBD, ligand-binding domain; NMDAR1, N-methyl-D-aspartate-receptor subunit NR1; NTD, N-terminal domain; $\mathrm{P}$, ion channel pore; TMD, transmembrane domains; xlp, extra-large pore domain. 

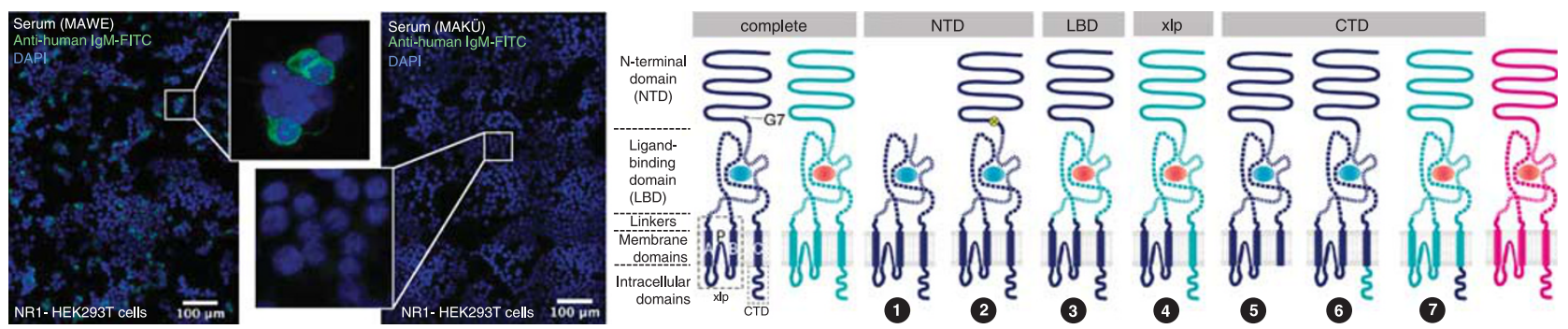

\begin{tabular}{|c|c|c|c|c|c|c|c|c|c|c|c|c|c|c|c|c|}
\hline \multirow{2}{*}{$I^{(a)}$} & \multirow{2}{*}{$A G E^{(b)}$} & \multirow{2}{*}{ GENDER } & \multirow{2}{*}{ DIAGNOSIS } & \multicolumn{3}{|c|}{ NMDAR1-AB } & \multirow{2}{*}{ GluN1-1b } & \multirow{2}{*}{ GluN2B } & \multirow{2}{*}{$\begin{array}{l}\text { GluN1-1b- } \\
\text { ANTD }\end{array}$} & \multirow{2}{*}{$\begin{array}{c}\text { GluN1-1b- } \\
\Delta \mathrm{G} 7\end{array}$} & \multirow{2}{*}{$\begin{array}{c}\text { GluN1-1b- } \\
\text { (LBD) } \\
\text { GluN2B } \\
\end{array}$} & \multirow{2}{*}{$\begin{array}{l}\text { GluN2B- } \\
\text { (xIp) } \\
\text { GluN1-1b } \\
\end{array}$} & \multirow{2}{*}{$\begin{array}{l}\text { GluN1-1b- } \\
\text { ACTD }\end{array}$} & \multirow{2}{*}{$\begin{array}{c}\text { GluN1-1b } \\
\text { (CTD) } \\
\text { GluN2B } \\
\end{array}$} & \multirow{2}{*}{$\begin{array}{l}\text { GluN2B- } \\
\text { (CTD) } \\
\text { GluN1-1b } \\
\end{array}$} & \multirow{2}{*}{ GluN2A } \\
\hline & & & & IG CLASS & TITER & EPITOPE & & & & & & & & & & \\
\hline MAKÜ & 81 & M & Hypertension & $\lg G$ & $1: 3200$ & LBD & + & - & + & + & - & - & + & + & - & $\lg M$ \\
\hline BLKA & 18 & $\mathrm{~F}$ & Encephalitis & $\lg G$ & $1: 1000$ & NTD (G7) & + & - & - & - & + & - & + & + & - & $\lg M$ \\
\hline GEJE & 27 & $\mathrm{~F}$ & Encephalitis & $\lg G$ & $1: 100$ & NTD (G7) & + & - & - & - & + & - & + & + & - & - \\
\hline MAWE & 85 & $\mathrm{~F}$ & Hypertension & $\lg M$ & $1: 3200$ & $\begin{array}{l}\mathrm{NTD}+\mathrm{CTD} / \\
\mathrm{LBD}+\mathrm{CTD}\end{array}$ & + & - & + & + & + & - & + & + & + & - \\
\hline JOMA & 72 & M & Hypertension & $\lg M$ & $1: 1000$ & $\begin{array}{l}\text { NTD+CTD/ } \\
\text { LBD+CTD }\end{array}$ & + & - & + & + & + & - & + & + & + & - \\
\hline ANFR & 83 & $\mathrm{~F}$ & Healthy & $\lg M$ & $1: 1000$ & NTD+LBD & + & - & + & + & + & - & + & + & - & - \\
\hline $\mathrm{CHSC}$ & 77 & $\mathrm{~F}$ & Hypertension & $\lg M$ & $1: 1000$ & $\begin{array}{l}\text { NTD+CTD/ } \\
\text { LBD+CTD }\end{array}$ & + & - & + & + & + & - & + & + & + & - \\
\hline ALMA & 37 & $\mathrm{~F}$ & Healthy & $\lg M$ & $1: 320$ & $\begin{array}{l}\text { NTD+CTD/ } \\
\text { LBD+CTD }\end{array}$ & + & - & + & + & + & - & + & + & + & $\lg M$ \\
\hline RELÜ & 67 & $\mathrm{~F}$ & Hypertension & $\lg M$ & $1: 1000$ & CTD & + & - & + & + & + & - & - & - & + & $\lg M$ \\
\hline GESC & 84 & M & Hypertension & $\lg A$ & $1: 1000$ & CTD & + & - & + & + & + & - & - & + & - & $\mathrm{Ig} G / M / A$ \\
\hline ANKL & 75 & $\mathrm{~F}$ & Hypertension & $\lg A$ & $1: 1000$ & CTD & + & - & + & + & + & - & - & - & + & $\lg G / M$ \\
\hline GEPA & 81 & $\mathrm{~F}$ & $\begin{array}{l}\text { Diabetes and } \\
\text { hypertension }\end{array}$ & $\begin{array}{l}\operatorname{Ig} A \\
\lg M\end{array}$ & $\begin{array}{l}1: 1000 \\
1: 1000\end{array}$ & $\begin{array}{l}\text { CTD } \\
\text { NTD+LBD }\end{array}$ & $\begin{array}{l}+ \\
+\end{array}$ & - & $\begin{array}{l}+ \\
+\end{array}$ & $\begin{array}{l}+ \\
+\end{array}$ & $\begin{array}{l}+ \\
+\end{array}$ & - & $\begin{array}{l}- \\
+\end{array}$ & $\begin{array}{l}- \\
+\end{array}$ & $\begin{array}{l}+ \\
-\end{array}$ & $\lg A$ \\
\hline MAZA & 78 & M & $\begin{array}{l}\text { Diabetes and } \\
\text { hypertension }\end{array}$ & $\begin{array}{l}\operatorname{Ig} A \\
\lg M\end{array}$ & $\begin{array}{l}1: 1000 \\
1: 100\end{array}$ & $\begin{array}{l}\text { NTD+LBD } \\
\text { CTD+x|p }\end{array}$ & $\begin{array}{l}+ \\
+\end{array}$ & $\begin{array}{l}- \\
-\end{array}$ & $\begin{array}{l}+ \\
+\end{array}$ & $\begin{array}{l}+ \\
+\end{array}$ & $\begin{array}{l}+ \\
+\end{array}$ & $\begin{array}{l}- \\
+\end{array}$ & $\begin{array}{l}+ \\
+\end{array}$ & $\begin{array}{l}+ \\
+\end{array}$ & $\begin{array}{l}- \\
+\end{array}$ & $\lg M$ \\
\hline M68-AB & - & - & Positive control & IgG (mouse) & $1: 1000$ & LBD & + & - & + & + & - & - & + & + & - & - \\
\hline
\end{tabular}

(a) Scrambled identification code; (b) Age at examination (years).

Figure 4. NMDAR1-AB recognize several GluN1-1b epitopes. The figure-table, summarizing the results of NMDAR1-AB epitope mapping, includes only seropositive individuals. Upper left: Representative tilescan confocal images of HEK293T cells transfected with NMDAR1 as used for serum testing are shown. NMDAR1-AB seropositivity (left) and seronegativity (right) is illustrated for IgM as example (anti-human IgM FITC-labeled as secondary antibody). Insets are $\times 4$ magnifications of the squared areas in their respective images. All images are Z-projections of 10 consecutive focal planes located $0.5 \mu \mathrm{m}$ apart and were taken under a confocal laser-scanning microscope using $\times 100$ oil objective (Leica TSC-SP5). Upper right: Schematic drawings of the different constructs used to transfect HEK293T cells (compare Figure 3). The first two constructs represent the complete version of the GluN1-1b and GluN2B subunits of NMDAR. The next seven constructs present deletions, mutations or replacements of defined regions, allowing identification of the epitopes recognized by NMDAR1-AB from healthy and ill individuals. Positivity $(+)$ or negativity $(-)$ for every construct in every sample is listed underneath. On the very right side, anti-GluN2A seropositivity/lg class is listed (anti-GluN2A titers range from 1:10 up to 1:200). AB, autoantibodies; CTD, C-terminal domain; Ig, immunoglobulin; NMDAR1, N-methyl-D-aspartate-receptor subunit NR1; NTD, N-terminal domain.

test $P$-values: IgG: $P<0.001$; IgM: $P<0.001$; $\lg \mathrm{A}: P=0.012$ and $\lg \mathrm{M}$ $+\operatorname{lgA}: P<0.001)$.

To investigate the impact of NMDAR1-AB on activity, glutamateevoked responses were evaluated in Xenopus laevis oocytes coexpressing human NR1-1/NR2A subunits. Only 6 min after exposure of oocytes to human sera, the AUC of the glutamateevoked response was significantly lower in seropositive compared with seronegative samples. This effect was sustained for at least 16 min (Figure 2c; one-way repeated-measures ANOVA: time $\times$ group interaction: $\mathrm{F}_{7,189}=7.431, P<10^{-6}$; Bonferroni post hoc correction for multiple comparison: only $P$-values $<0.05$ are shown). Evaluating Ig classes separately, the significant global effect remained (one-way repeated-measures ANOVA: time $\times$ group interaction: $F_{35,168}=1.98 ; P=0.002$; Figure 2c, left lower graph).

Epitope mapping using seven different NMDAR1 constructs (Figures $3 a$ and $b$ ) revealed recognition by the NMDAR1-ABpositive sera of different epitopes, located in the extracellular ligand-binding domain and N-terminal domain (NTD) as well as the intracellular C-terminal domain (CTD) and extra-large pore domain (xlp). NMDAR1-AB seropositivity was polyclonal/polyspecific in 7/14 sera and likely mono- or oligoclonal/oligospecific (mainly lgG) in $7 / 14$. Whereas no GluN2B-AB (0/14) was found,
GluN2A-AB (9/14) was frequently detected in the NMDAR1-ABpositive sera (Figure 4). Separate exploratory analyses of GluN2A$A B$ carrier versus non-carrier sera regarding internalization assay and electrophysiology results did not reveal differences. Overall, no particular disease-related pattern appeared.

The G7 site of the NTD, an epitope believed to be crucial for NMDAR1-AB found in encephalitis, ${ }^{25}$ was recognized in $2 / 10$ sera binding to NTD (Figure 4, negativity for construct 2). Since these sera were from two anti-NMDAR encephalitis cases reported previously (without epitope mapping), ${ }^{8}$ we tested another seven sera from anti-NMDAR encephalitis patients specifically for this epitope. All seven sera had NMDAR1-AB of two Ig classes. Epitope location in NTD was seen in 5/7 sera for lgG, with $4 / 7$ recognizing G7. IgM and IgA recognized other epitopes, as did IgG in 2/7 sera (not further determined due to lack of material) (Figure 3c).

\section{DISCUSSION}

The present paper systematically analyzed for the first time NMDAR1-AB of three Ig classes (IgM, IgG and $\lg A$ ), derived from randomly selected individuals of different age, gender and medical condition, regarding in vitro functionality and epitope location. All NMDAR1-AB-positive sera tested led to NMDAR1 
internalization in IPSC-derived human cortical neurons and to reduced glutamate-evoked response in NR1-1b/NR2A-expressing oocytes. Several different epitopes were identified, located in the extracellular part of NMDAR1 (NTD, ligand-binding domain) or intracellular, CTD and in the xlp, which were recognized by NMDAR1-AB of the $\lg G, \lg A$ and IgM class. Importantly, there was no consistent functional or epitope pattern detectable regarding Ig class or health/disease state.

In light of the comparable functionality of all NMDAR1-AB tested here, the high seroprevalence (up to $>20 \%$ ) of NMDAR1-AB is even more puzzling and may indicate a previously unknown dimension of 'physiological autoimmunity' that increases with age. ${ }^{9-13}$ But what are the inducers of such abundant formation of NMDAR1-AB that potentially influence brain function? So far, associations were found with certain forms of cancer, mainly ovarian teratoma, ${ }^{5}$ influenza $A$ and $B,{ }^{9-13}$ as well as with $a$ genome-wide significant marker on chromosome 1, rs524991, ${ }^{9}$ close to NFIA, a transcription factor mediating neuroprotective effects of NMDAR. ${ }^{26}$ There are certainly more hitherto unknown predisposing factors for carrying these $A B$. Broader significance of NMDAR1-AB is underscored by their presence in mammalians other than humans. ${ }^{27}$ This is less surprising in view of the substantial seroprevalence also of other brain-directed $A B$ in species like rabbits, pigs and cows. ${ }^{28}$

While irrespective of the epitope, all 14 NMDAR1-AB-positive sera investigated here $(\lg M, \lg G, \lg A)$ revealed similar $A B$ functionality (internalization, electrophysiology), the $A B$-inducing factors may have determined the epitopes via mechanisms like molecular mimicry. ${ }^{29,30}$ Published work on NMDAR1-AB epitopes is scarce ${ }^{25,31,32}$ and focused on IgG recognizing NTD and the NTD$\mathrm{G} 7$ domain $\left(\mathrm{N}^{368} / \mathrm{G}^{369}\right)$, probably because this region and Ig class was first deemed pathognomonic for anti-NMDAR-encephalitis. ${ }^{5,25}$ Indeed, the sera investigated here of two young females with diagnosed anti-NMDAR-encephalitis, originally reported within a series of schizophrenia cases, ${ }^{8}$ also recognized this epitope, however, without sticking out functionally (that is, regarding internalization or electrophysiology). Therefore, we analyzed sera of seven additional young female patients, diagnosed with antiNMDAR encephalitis (4/7 with ovarian teratoma), in an NTD-G7targeted epitope screen. Interestingly, all 7 subjects carried NMDAR1-AB of 2 lg classes, but only lgG recognized NTD or NTD-G7 in 5/7 sera. Similarly, in a recent study on young females with neuropsychiatric manifestation of systemic lupus erythematosus, two epitopes in the NTD (outside G7) were recognized by NMDAR1-AB (only lgG tested). Regrettably, NTD was the only mapped region, functionality was not evaluated, and instead of a cell-based assay, the accepted gold standard, an ELISA was used. ${ }^{32}$ Together, these data suggest that factors predisposing young women to neuropsychiatric manifestations of NMDAR-associated autoimmunity are connected with NTD or NTD-G7 epitopes. The accentuated role of $\mathrm{lgG}$ in this context is still a matter of speculation but may be related to inflammation-induced classswitch in the brain. ${ }^{33}$ Regarding NMDAR1-AB of the IgA class, a single study, mapping epitopes of two female patients, found in one of them evidence of NTD/G7 as a target epitope (likely among other epitopes). ${ }^{31}$ Interestingly, the significance of $A B$ for brain manifestation of lupus erythematosus seems still debatable. In a recent study, lack of $B$ cells and autoantibodies in a murine model of systemic lupus did not prevent the development of key features of neuropsychiatric lupus. ${ }^{34}$

To conclude, all naturally occurring serum NMDAR1-AB obviously have pathogenic potential. For still unexplored reasons, they are highly frequent and their prevalence increases with age. NMDAR-AB seropositivity alone definitely does not justify immunosuppressive treatment. Syndromal relevance of serum NMDAR1-AB depends on accessibility to the brain, that is, blood-brain-barrier permeability. ${ }^{9,11,13,15}$ This permeability might differ regionally, thereby explaining individually variable symptomatic consequences. ${ }^{2}$ Moreover, inflammation in the brain likely has a crucial role in determining syndrome acuteness and severity as contributed by circulating NMDAR1-AB and respective plasma cells, including boost in $A B$ titers (upon epitope recognition) and class-switch to $\operatorname{lgG}^{33}$ Especially in individuals where an overt encephalitis diagnosis is unlikely, determination of blood-brain-barrier disruption, for example, by a novel magnetic resonance imaging method, ${ }^{35}$ may prove helpful for estimating necessity and benefit of immunosuppressive therapeutic interventions.

\section{CONFLICT OF INTEREST}

The authors declare no conflict of interest.

\section{ACKNOWLEDGMENTS}

This work was supported by the Max Planck Society, the Deutsche Forschungsgemeinschaft (Center for Nanoscale Microscopy \& Molecular Physiology of the Brain), EXTRABRAIN EU-FP7 and the Niedersachsen-Research Network on Neuroinfectiology (N-RENNT). The assistance by the UMG-Stem Cell Unit (S. Chen and L. Cyganek) is greatly appreciated.

\section{AUTHOR CONTRIBUTIONS}

$\mathrm{HE}, \mathrm{MH}$ and $\mathrm{DB}$ contributed to concept and design of the study. ECG, BO, DT, $\mathrm{SB}, \mathrm{RT}, \mathrm{PZ}, \mathrm{JS}, \mathrm{CK}, \mathrm{HoP}, \mathrm{BJ}, \mathrm{HP}, \mathrm{WHZ}, \mathrm{DB}, \mathrm{MH}$ and $\mathrm{HE}$ contributed to data acquisition/analysis/interpretation. $\mathrm{HE}, \mathrm{ECG}, \mathrm{BO}, \mathrm{DT}$ and $\mathrm{MH}$ contributed to drafting manuscript and figures. All authors read and approved the final version of the manuscript.

\section{REFERENCES}

1 Sutton I, Winer JB. The immunopathogenesis of paraneoplastic neurological syndromes. Clin Sci 2002; 102: 475-486.

2 Diamond B, Huerta P, Mina-Osorio P, Kowal C, Volpe B. Losing your nerves? Maybe it's the antibodies. Nat Rev Immunol 2009; 9: 449-456.

3 Coutinho E, Harrison P, Vincent A. Do neuronal autoantibodies cause psychosis? A neuroimmunological perspective. Biol Psychiatry 2014; 75: 269-275.

4 Crisp SJ, Kullmann DM, Vincent A. Autoimmune synaptopathies. Nat Rev Neurosci 2016; 17: 103-117.

5 Dalmau J, Gleichman AJ, Hughes EG, Rossi JE, Peng X, Lai M et al. Anti-NMDAreceptor encephalitis: case series and analysis of the effects of antibodies. Lancet Neurol 2008; 7: 1091-1098.

6 Wandinger KP, Saschenbrecker S, Stoecker W, Dalmau J. Anti-NMDA-receptor encephalitis: a severe, multistage, treatable disorder presenting with psychosis. J Neuroimmunol 2011; 231: 86-91.

7 Zandi MS, Irani SR, Lang B, Waters P, Jones PB, McKenna P et al. Disease-relevant autoantibodies in first episode schizophrenia. J Neurol 2011; 258: 686-688.

8 Steiner J, Walter M, Glanz W, Sarnyai Z, Bernstein HG, Vielhaber S et al. Increased prevalence of diverse $\mathrm{N}$-methyl-D-aspartate glutamate receptor antibodies in patients with an initial diagnosis of schizophrenia: specific relevance of IgG NR1a antibodies for distinction from N-methyl-D-aspartate glutamate receptor encephalitis. JAMA Psychiatry 2013; 70: 271-278.

9 Hammer C, Stepniak B, Schneider A, Papiol S, Tantra M, Begemann M et al. Neuropsychiatric disease relevance of circulating anti-NMDA receptor autoantibodies depends on blood-brain-barrier integrity. Mol Psychiatry 2013; 19: 1143-1149.

10 Dahm L, Ott C, Steiner J, Stepniak B, Teegen B, Saschenbrecker S et al. Seroprevalence of autoantibodies against brain antigens in health and disease. Ann Neurol 2014; 76: 82-94.

11 Zerche M, Weissenborn K, Ott C, Dere E, Asif AR, Worthmann H et al. Preexisting serum autoantibodies against the NMDAR subunit NR1 modulate evolution of lesion size in acute ischemic stroke. Stroke 2015; 46: 1180-1186.

12 Steiner J, Teegen B, Schiltz K, Bernstein H-G, Stoecker W, Bogerts B. Prevalence of $\mathrm{N}$-methyl-D-aspartate receptor autoantibodies in the peripheral blood: healthy control samples revisited. JAMA Psychiatry 2014; 71: 839.

13 Castillo-Gomez E, Kastner A, Steiner J, Schneider A, Hettling B, Poggi G et al. The brain as 'immunoprecipitator' of serum autoantibodies against NMDAR1. Ann Neurol 2015; 79: 144-151.

14 Busse S, Busse M, Brix B, Probst C, Genz A, Bogerts B et al. Seroprevalence of $\mathrm{N}$-methyl-D-aspartate glutamate receptor (NMDA-R) autoantibodies in aging 
subjects without neuropsychiatric disorders and in dementia patients. Eur Arch Psychiatry Clin Neurosci 2014; 264: 545-550.

15 Hammer C, Zerche M, Schneider A, Begemann M, Nave KA, Ehrenreich H. Apolipoprotein E4 carrier status plus circulating anti-NMDAR1 autoantibodies: association with schizoaffective disorder. Mol Psychiatry 2014; 19: 1054-1056.

16 Moscato EH, Peng X, Jain A, Parsons TD, Dalmau J, Balice-Gordon RJ. Acute mechanisms underlying antibody effects in anti-N-methyl-D-aspartate receptor encephalitis. Ann Neurol 2014; 76: 108-119.

17 Begemann M, Grube S, Papiol S, Malzahn D, Krampe H, Ribbe K et al. Modification of cognitive performance in schizophrenia by complexin 2 gene polymorphisms. Arch Gen Psychiatry 2010; 67: 879-888.

18 Toyka K, Brachman D, Pestronk A, Kao I. Myasthenia gravis: passive transfer from man to mouse. Science 1975; 190: 397-399.

19 Streckfuss-Bomeke K, Wolf F, Azizian A, Stauske M, Tiburcy M, Wagner S et al. Comparative study of human-induced pluripotent stem cells derived from bone marrow cells, hair keratinocytes, and skin fibroblasts. Eur Heart $J$ 2013; 34: 2618-2629.

20 Shi Y, Kirwan P, Livesey FJ. Directed differentiation of human pluripotent stem cells to cerebral cortex neurons and neural networks. Nat Protoc 2012; 7: 1836-1846.

21 Schindelin J, Arganda-Carreras I, Frise E, Kaynig V, Longair M, Pietzsch T et al. Fiji: an open-source platform for biological-image analysis. Nat Methods 2012; 9: 676-682.

22 Hogg RC, Bandelier F, Benoit A, Dosch R, Bertrand D. An automated system for intracellular and intranuclear injection. J Neurosci Methods 2008; 169: 65-75.

23 Ho S, Hunt H, Horton R, Pullen J, Pease L. Site-directed mutagenesis by overlap extension using the polymerase chain reaction. Gene 1989; 77: 51-59.

24 Wurch $T$, Lestienne F, Pauwels P. A modified overlap extension PCR method to create chimeric genes in the absence of restriction enzymes. Biotechnol Tech 1998; 12: 653-657.

25 Gleichman AJ, Spruce LA, Dalmau J, Seeholzer SH, Lynch DR. Anti-NMDA receptor encephalitis antibody binding is dependent on amino acid identity of a small region within the GluN1 amino terminal domain. J Neurosci 2012; 32: 11082-11094.

26 Zheng S, Eacker SM, Hong SJ, Gronostajski RM, Dawson TM, Dawson VL. NMDAinduced neuronal survival is mediated through nuclear factor I-A in mice. J Clin Invest 2010; 120: 2446-2456.
27 Pruss H, Leubner J, Wenke NK, Czirjak GA, Szentiks CA, Greenwood AD. AntiNMDA receptor encephalitis in the polar bear (Ursus maritimus) Knut. Sci Rep 2015; 5: 12805.

28 DeMarshall C, Sarkar A, Nagele EP, Goldwaser E, Godsey G, Acharya NK et al. Utility of autoantibodies as biomarkers for diagnosis and staging of neurodegenerative diseases. Int Rev Neurobiol 2015; 122: 1-51.

29 Diamond B, Honig G, Mader S, Brimberg L, Volpe BT. Brain-reactive antibodies and disease. Annu Rev of Immunol 2013; 31: 345-385.

30 Bhat R, Steinman L. Innate and adaptive autoimmunity directed to the central nervous system. Neuron 2009; 1: 123-132.

31 Doss S, Wandinger KP, Hyman BT, Panzer JA, Synofzik M, Dickerson B et al. High prevalence of NMDA receptor $\operatorname{lgA} / \mathrm{lgM}$ antibodies in different dementia types. Ann Clin Transl Neurol 2014; 1: 822-832.

32 Ogawa E, Nagai T, Sakuma Y, Arinuma Y, Hirohata S. Association of antibodies to the NR1 subunit of $\mathrm{N}$-methyl-D-aspartate receptors with neuropsychiatric systemic lupus erythematosus. Mod Rheumatol 2015; 1: 1-7.

33 Zhang J, Jacobi AM, Wang T, Berlin R, Volpe BT, Diamond B. Polyreactive autoantibodies in systemic lupus erythematosus have pathogenic potential. J Autoimmun 2009; 33: 270-274.

34 Wen J, Doerner J, Chalmers S, Stock A, Wang H, Gullinello M et al. B cell and/or autoantibody deficiency do not prevent neuropsychiatric disease in murine systemic lupus erythematosus. J Neuroinflammation 2016; 13: 73.

35 Montagne A, Barnes SR, Sweeney MD, Halliday MR, Sagare AP, Zhao Z et al. Blood-brain barrier breakdown in the aging human hippocampus. Neuron 2015; 85: $296-302$

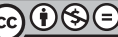

This work is licensed under a Creative Commons AttributionNonCommercial-NoDerivs 4.0 International License. The images or other third party material in this article are included in the article's Creative Commons license, unless indicated otherwise in the credit line; if the material is not included under the Creative Commons license, users will need to obtain permission from the license holder to reproduce the material. To view a copy of this license, visit http:// creativecommons.org/licenses/by-nc-nd/4.0/

(c) The Author(s) 2017 